\title{
ASO Author Reflections: Similar Short- and Long-Term Outcomes in Variable Use and Timing of Restaging MRI and Surgery After Preoperative Chemoradiotherapy for Rectal Cancer
}

\author{
Robin Detering, $\mathrm{MD}^{1}$, and Pieter J. Tanis, $\mathrm{MD}, \mathbf{P h D}^{1}$ \\ Department of Surgery, Amsterdam UMC, University of Amsterdam, Amsterdam, The Netherlands
}

\section{PAST}

Preoperative chemoradiotherapy (CRT) has become standard of care in the treatment of patients with locally advanced rectal cancer. CRT results in downsizing facilitating complete resection and reduces the local recurrence rate, and $15-20 \%$ of patients achieve pathological complete response ( $\mathrm{pCR}$ ), which is associated with favorable oncological outcomes. ${ }^{1}$ However, one of the unresolved issues regarding preoperative CRT is the optimal time interval to total mesorectal excision (TME) surgery and the role of magnetic resonance imaging (MRI) restaging in clinical decision-making.

Studies have reported conflicting results regarding the association between the CRT-surgery interval and outcome parameters such as pathological response, specimen quality, margin status, and postoperative morbidity. ${ }^{2}$ Regarding MRI restaging, optimal methodology, timing, interpretation, and clinical relevance are still being discussed.

This ASO Author Reflections is a brief invited commentary on the article, "Cross-Sectional Study on MRI Restaging after Chemoradiotherapy and Interval to Surgery in Rectal Cancer: Influence on Short- and Long-Term Outcomes," Ann Surg Oncol. (2019). https://doi.org/10.1245/s10434-018-07097-7.

(C) The Author(s) 2019

First Received: 27 February 2019;

Published Online: 7 March 2019

R. Detering, MD

e-mail: r.detering@amc.uva.nl
Therefore, the purpose of this cross-sectional study was to evaluate firstly variation in practice with respect to MRI restaging and its impact on time interval to surgery, and secondly the impact of timing of surgery on pathological, surgical, and long-term oncological outcomes.

\section{PRESENT}

At the population level, high use of restaging MRI after CRT with substantial variability in timing was observed in patients with locally advanced rectal cancer, which was not supported by guideline recommendations at that time. ${ }^{3}$ Also, substantial variability in the time interval between start of CRT and surgery was observed, partially related to differences in patient and tumor characteristics. The impact of MRI restaging on clinical decision-making was difficult to determine based on this retrospective study. Using the median CRT-surgery interval of 14 weeks as a cutoff, similar postoperative and long-term surgical and oncological outcomes were found for the two interval groups. This real-world evidence does not point towards an optimal CRT-surgery interval, but stresses the importance of a tailored approach within a multidisciplinary setting. The heterogeneity within locally advanced rectal cancer and the response to therapy questions the value of conducting randomized controlled trials (RCTs) like the GRECCAR-6 trial that aim to define just one optimal time interval. ${ }^{2}$

\section{FUTURE}

Nowadays, the impact of response evaluation by MRI restaging and timing of subsequent treatment after CRT would be different, aiming at identifying clinical complete responders who are candidates for a watch-and-wait policy. ${ }^{4}$ For the majority of patients still requiring (beyond) 
TME surgery after CRT, studies using standardized diffusion-weighted MRI restaging with structured MRI reporting at specified time intervals are needed to define the impact on clinical decision-making and subsequent outcome. ${ }^{5}$ One of the unresolved questions is whether the type of resection is influenced by MRI restaging. Is it safe to change from total exenteration to only "shaving" of the prostate, or from abdominoperineal resection to sphinctersaving surgery based on significant shrinkage of the tumor on MRI? Regarding CRT-surgery interval, patient randomization in future RCTs should be performed after MRI response assessment, in order to determine the impact of timing of surgery on margin status, morbidity, and oncological outcome within homogeneous subgroups of locally advanced rectal cancer.

DISCLOSURE The authors declare that they have no conflict of interest.

OPEN ACCESS This article is distributed under the terms of the Creative Commons Attribution 4.0 International License (http://crea tivecommons.org/licenses/by/4.0/), which permits unrestricted use, distribution, and reproduction in any medium, provided you give appropriate credit to the original author(s) and the source, provide a link to the Creative Commons license, and indicate if changes were made.

\section{REFERENCES}

1. Martin ST, Heneghan HM, Winter DC. Systematic review and meta-analysis of outcomes following pathologic complete response to neoadjuvant chemoradiotherapy for rectal cancer. $\mathrm{Br}$ J Surg. 2012;99:918-28.

2. Lefevre JH, Mineur L, Simon T, et al. Effect of interval (7 or 11 weeks) between neoadjuvant radiochemotherapy and surgery on complete pathologic response in rectal cancer: a multicenter, randomized, controlled trial (GRECCAR-6). J Clin Oncol. 2016;34:3773-3780.

3. Detering R, Borstlap WAA, Broeders L, et al. Cross-sectional study on MRI restaging after chemoradiotherapy and interval to surgery in rectal cancer; influence on short and long-term outcomes. Ann Surg Oncol. 2019. https://doi.org/10.1245/s10434 -018-07097-7.

4. Beets GL, Figueiredo NL, Habr-Gama A, et al. A new paradigm for rectal cancer: organ preservation: introducing the international watch and wait database (IWWD). Eur $J$ Surg Oncol. 2015;41(12):1562-4.

5. Beets-Tan RGH, Lambregts DMJ, Maas M, et al. Magnetic resonance imaging for clinical management of rectal cancer: updated recommendations from the 2016 European Society of Gastrointestinal and Abdominal Radiology (ESGAR) consensus meeting. Eur Radiol. 2018;28:1465.

Publisher's Note Springer Nature remains neutral with regard to jurisdictional claims in published maps and institutional affiliations. 